\title{
The look as a medium: A conceptual framework and an exercise for teaching visual studies
}

Asko Lehmuskallio, University of Tampere, Tampere, Finland

New Social Research/COMET Research Centre, Faculty of Communication Sciences, FI-33014

University of Tampere, Finland; asko.lehmuskallio@uta.fi

\begin{abstract}
The paper considers the particular value of focusing on the look as a medium when studying visual cultures. This focus is helpful for coming to terms with distinct understandings of the visual. To address the look as a medium, four analytical dimensions are introduced for distinguishing among separate but closely interrelated visual phenomena: the look becomes understandable via its mediations, some media are explicitly created to be looked at, the look itself acts as a medium of images, and looking is a skilled practice that must be learned. In light of the approach outlined, an exercise is presented for teaching the look as a medium at university level: this exercise in 'looking into each other's eyes' is applied with the aim of sparking interest in the topic and stimulating debate on its various dimensions. Thus, it is intended to be generative, an exercise to think with.
\end{abstract}

\section{Keywords}

Visual cultures; photography; skilled vision; medium; faces 


\section{Introduction}

Studies of visual cultures often bear the term 'visual' because they deal with artefacts that have been created to be looked at. These artefacts, whether photographs, paintings, posters, mirrors, or diagrams, may be studied with various methods, ranging from the iconographic and iconological to interview-based and ethnographic methods. While iconographic and iconological analyses pay specific attention to the pictures to be studied, foregrounding what is made visible, the interest expressed via interview-based and ethnographic methods tends to centre less on the visual content of individual pictures and more on the contexts in which they are created and used. In my research and teaching on visual cultures, I have found that a focus on the look as a medium has been particularly insightful for bridging gaps between the knowledge gained by the methods mentioned. This is so because studying the look as a medium assists in paying attention to both images and their contextual uses, by stressing the interrelations between images and those looking at them. Acknowledging this multifaceted relationship is particularly relevant in reminding that a given picture sometimes may be seen very differently by different people, not just in how it is interpreted but also in what actually gets seen. Two people looking at the same visual medium may not see the same image but might be quite literally looking at different images. A focus on the look, and the ways in which it is mediated, encourages paying attention to what gets seen, and in which ways.

Here, I will introduce a framework for addressing the look as a medium, focusing on 1) how the look becomes understandable via its mediations, 2) visual media as media created to be looked at, 3) how the look operates as a medium of images, and 4) how looking is a skilled practice that needs to be learned. After this, I will present a visual exercise that can serve as a medium to spark reflection on the look as a medium and will discuss it in light of the framework presented. 


\section{The look rendered understandable via its mediations}

What people look at, for how long, and with what kinds of intentions and associated thoughts has long puzzled humans. What is she looking at? Why? What interest is involved in looking at that? Such questions have surely been posed countless times throughout history, in a wide variety of locales.

To disentangle these questions, we need to understand how the look becomes understandable, asking questions such as: What is a look? How do you actually know what other people look at, or even are able to see? Or what is it that in any given moment you yourself look at or can see? I suggest that these questions are fruitfully approached by focusing on the mediations - the means by which looks and looking become understandable. To more closely examine what a look is, we need to approach it via its various media.

The understanding of a medium applied here follows a medium-theoretical stance oriented toward processual descriptions of how an act, such as looking, is accomplished. In this understanding, 'medium' refers to an in-between, which is needed for an action to unfold. While a medium may take various forms, media (as a plural of medium) for a specific situational action are limited in practice. From this perspective, looking is approached via its mediations, not directly as a look itself. The look serves thus a dual role: on one hand, the images that we see become visible via the medium of a look, while on the other, the look itself is mediated, being not straightforwardly visible. It is rather part of our visual perception, and thus part of what we do not have direct access to. As Tim Ingold, a perceptive writer on skill, traces, and perception, has noted, 'the one thing we cannot perceive is perception itself' (2000, p. 243). 
To understand the look as a medium, we need to trace how it situationally mediates images, and how it itself becomes understandable, by focusing on specific empirical phenomena. The act of looking is here understood as the direction of one's eyes and attention to seeing someone or something. In interpersonal conversation, we might, for example, try to follow the path of our conversation partners' eye movements, focusing on the movements of the pupil across the sclera for an understanding of what someone is looking at. Yet considering eye movements alone is not sufficient for understanding the look; one needs also to get an understanding of the kind of attention involved in directing one’s eyes towards something to be seen (Bundesen \& Habekost, 2008). On one hand, an examining look might pay close attention to details of a particular painting, attention that might be traced by following the direction of one's eye movements. On the other hand, one might, for example, cast the eyes upward and raise one's head toward the blue sky when thinking about a difficult question, actually failing to see the movement of the passing clouds or the flock of birds that are in one's line of sight. These would be immediately visible if they were attended to.

While the noun 'look’ often also denotes someone’s appearance, especially when used in combination with a qualifying adjective (e.g., in statements that a person has a beautiful, stylish, personal, or frightened look), this usage hints toward ways in which our ways of looking may be captured, seduced, or taken hold of in very particular ways. One’s appearances may be arranged, and ordered, so as to spark specific interrelations among those seeing and those being seen. For instance, the 'male gaze', the 'Oriental gaze', and the 'spectator gaze' are concepts developed in the 1970s and 1980s to address how specific visual media are geared for idealised spectators, who may take up and replicate in their actions a specific kind of looking (Rose, 2011). These qualifying looks remain of great interest for many scholars of visual cultures, especially since there continues to be discussion on how a particular act of looking may, or may not, be part of broader visual orders (Seppänen, 2006). 
Since the look is approached via its mediations, we must work from an understanding of the medium that does not rely principally on ontological separation of media one from another (categories of television, film, and newspapers, for example). Rather, we should attend to the situational attachments and infrastructural interrelations within which something mediates while something else does not. This understanding expands the scope of what may be considered a medium. Though this notion of medium may seem counterintuitive at first, it finds support also among well-regarded media and communication scholars, such as John Durham Peters (2015, loc. 182):

Our data media have won just as much of a planet-steering role as have more basic nature-engineering media such as burning, farming, herding, or building. Every medium, whether our bodies or our computers, is an ensemble of the natural and the artificial, and WikiLeaks, corn syrup, whale oil, squids, Facebook, jet lag, weather forecasts, and bipedal posture are some of the parts that belong to media theory.

The look can easily be included on this list, but understanding the look as a medium is useful not because that list might possibly be expanded ad infinitum but because the idea of look as medium offers a particularly good lens on our visual cultures - and also the visual cultures of others.

The interrelations between the look and its mediations, framed in terms of the body and technology, are spelt out in Optical Media, in which Friedrich Kittler posits that 'we knew nothing about our senses until media provided models and metaphors' (2010, p. 34). This suggests that our understanding of our perception is tied to the media we have at hand for reflecting on it, and, indeed, the history of our attempts to understand vision is just as much a history of the technologies we use to study vision. Optical devices, such as camerae obscurae, have offered commentators 
numerous models and metaphors for understanding how human vision works. This interrelation is nevertheless not straightforward, as Jonathan Crary has shown. For instance, for René Descartes, the camera obscura was an aid in explaining how the human mind works: '[a] conception of the human mind as an inner space in which both pains and clear and distinct ideas passed in review before an Inner Eye... The novelty was the notion of a single inner space in which bodily and perceptual sensations... were objects of quasi-observation’ (Crary, 1992, p. 43, citing Richard Rorty). Karl Marx and Sigmund Freud, in turn, working two centuries later, used the camera obscura to explain what Crary termed 'a model for procedures and forces that conceal, invert, and mystify truth’ (1992, p. 29). In both cases, the camera obscura was a useful medium for reflection on how vision and human understanding work, while the conclusions of these reflections were very different.

While the look is here considered to become understandable via its mediations, the understanding generated is necessarily partial, and may be interpreted differently, depending on the broader analytical framework within which specific observations are connected.

\section{Visual media as explicitly created to be looked at}

While our environments are filled with material - human-made and natural objects alike - that may be looked at, humans have long paid specific attention to some forms of media as visual media: as media to be looked at. While we orient our entire sensory apparatus towards that which we apprehend, thereby hearing, feeling, smelling, tasting, and seeing whatever we focus our attention on, the specificity of visual media is that they have been created to be looked at. These media bear an imprint of an aesthetic difference (Bredekamp, 2015, p. 35), a surplus that is not purely functional. Early hand axes already bore traces of this aesthetic difference around 200,000 years ago. For 
instance, one found in West Tofts, with a fossilised clam at its very centre, clearly displays purposeful decoration (Bredekamp, p. 36).

Archaeology provides us with numerous fascinating examples. Alongside found objects that have been modelled to carry an aesthetic difference are our bodies, especially our faces, which became particularly important surfaces for visual media quite early on. Our bodies are sites both for seeing and for displaying images, and should not be forgotten in discussions of visual media. Several examples of decorated skulls exist in support of the contention that the human head, its frontal area in particular, has long been considered to offer valuable surfaces for meaningful images (Belting, 2014). While the face has played an important role as a visual medium for many millennia, it became important for symbolic articulations and as a marker of identity only once freed from prehension tasks, as André Leroi-Gourhan (1993) has shown. Bipedal, erect locomotion; use of the hands for technical manipulation; and the discovery and invention of techniques connected with crafting of physical artefacts afforded the facial organs' development of audible articulate speech and visible facial expressions. With time, our faces became shorter and the roots of our front teeth shrank, making our faces less suited to acts of prehension and simultaneously widening the spectrum of possible symbolic expressions.

With these changes in mind, some authors have found the human face to be an image par excellence, since it is a temporary result of a co-evolutionary process that has become a particularly noteworthy visual medium for dense symbolic expression, allowing us to use our faces for creating a wide variety of images. The diversity of emotions that can be expressed with our faces and the multitudes of social attributes that we may carry on our faces to show that we belong to specific groups or modes of thought together provide ample examples of the potential of our faces to act as visual media. 
Today, we encounter diverse visual media, many of which continue to carry images of faces, such as those inscribed in coins, statues, portrait paintings, photographs, film posters, or digitally networked selfie photographs. Hans Belting (2011) refers to these exteriorisations of facial images to other media as images in effigy, while images that we carry with us on our bodies are images in corpore. The distinction between images in effigy (e.g., a portrait painting or photograph) and images in corpore (e.g., a situational grimace on one's physical face) is especially useful in our efforts to identify the intrinsic differences borne by visual media. While an image on our bodies may last a few seconds before the facial expressions are lost, for example, when we facially react to something we find particularly pleasing or disgusting, images in effigy, taken of the same situation in a split second with a photographic camera on glass-plate film, may last several hundred years if the image captured is processed correctly and later stored appropriately. The image conveyed may be largely the same between the two cases, but the differences in visual media point to very different orders of life span between distinct visual media.

\section{The look as a medium of images}

Focusing on the look as a medium leads us to the question of what kinds of images this perspective allows us to see. A common assumption surrounding images is that they are polysemous and may be interpreted differently on the basis of the specific situation in which they are seen and the cultural background of those looking at them. Hence, a photograph showing two people, a naked adult and child seated in an old smoke sauna, might be interpreted in Finland as an image dense with symbolic meanings, such as those associated with the importance of visiting the sauna bath (in connection with this location's historical importance in birth and in leaving the world, as well as celebrating the strengthening of social ties that going to the sauna allows for). This image might be interpreted in a very different vein, however, by someone without knowledge of local customs and 
traditions: it could be interpreted as a very problematic picture, one that inappropriately displays nudity, signals possible sexual relations between adults and children, and depicts architectural solutions that may not comply with modern safety regulations. In work along similar lines, Catherine Lutz and Jane Collins (1993) have studied how photographs published in National Geographic may be understood as an intersection of several kinds of looks, depending on whose interpretations one asks for. Attending to these different ways of seeing is particularly valuable since work of this sort allows us to understand the wide variety of interpretations that a specific image may call forth.

While images may be interpreted differently, the studies highlighting this variety tend to assume that everyone involved is actually seeing the same images. Studies of how our eyes are used for seeing have offered examples of cases in which the same visual media are looked at, but very different images are actually seen. A classic example is found in a study by Alfred Yarbus (1965/1967), who carried on the development of eye-tracking technology in the 1960s to inform understanding of the interrelations between eye movements and vision. He was able to trace the location of the pupil against the white sclera of the eye and hence estimate where exactly a person was looking at. Studies of this kind called into question the assumption that human vision would function in the manner of a camera obscura, or a photographic camera, as other scholars had argued, and were helpful in drawing attention to the foveal area of the visual field, which allows us to see sharply. Yarbus took note of the various locations of the pupil against the sclera when his research subjects were looking at a specific visual medium. These locations, called fixation points, were connected, with lines between them suggesting movement between one fixation point and another. So instead of seeing an image holistically, without any strict order, as was suggested by understandings of the look encouraged by the medium of the camera (think only of the idea of releasing the shutter of a camera, leaving it open for a specified amount of time, and then closing it in order to record a 
photographic image), the use of eye-tracking technology revealed very specific successive motions and patterns in looking at pictures. Furthermore, Yarbus noticed that, even when his subject's eyes were fixed on one small part of a visual medium, such as a face in a painting, the pupil did not remain in one location. It continuously moved about within a smaller area, leaving traces that are called micro-saccadic movements. Such observations are helpful in pointing out that viewers actually see even so-called still images - images presented via visual media that do not move, as in the case of a printed photograph hanging on a wall - as moving images. One can thereby question the usefulness of a strict division between still and moving images, since images cannot be seen without movement.

More significantly, Yarbus asked his research subjects to look at a copy of a famous Russian painting, Ilya Repin’s Unexpected Visitor, both freely and after having been assigned specific tasks. He noticed that the fixation points, as well as the movements between them, changed significantly, depending on the task given. For example, when subjects were asked the ages of the people depicted or were instructed to remember the positions of people and objects in the room, the tracings recorded focused on different areas of the visual medium, suggesting that for the two tasks the research subjects saw two, different images, even though looking at the same visual medium.

This phenomenon later received more specific attention, most famously perhaps from Arien Mack and Irvin Rock (1998), who coined the term 'inattentional blindness' to describe the inability to perceive a visual stimulus in plain sight that arises from situational inattention. Daniel Simons and Christopher Chabris (1999) devised a 'gorilla test' to show how involvement in task-related activities leads to sustained inattentional blindness over a longer time, with their famous example involving perceptual blindness to a dancing gorilla among people tasked with counting relatively quick passes of a ball between members of a team. The gorilla test has received a reasonable amount 
of public attention, with versions of it having been created for such purposes as a public-service announcement aimed at car drivers, for specifically paying attention to cyclists.

These examples show how specific ways of directing one's eyes and attention play a significant role in what actually gets seen. The ways in which we look, for how long, at what, and with what kinds of interests all have an impact on the images we seek. Hence, the look itself is a particularly important medium to consider.

\section{Looking as a skilled practice}

While situational tasks and cultural backgrounds influence what gets seen and how the seen is interpreted, both represent parts of human activity that require learning. Learning to pay attention to the mediations that make the look understandable, to distinguish on the basis of differences in visual media, and to understand the look as a medium of images involves skills that do not come easily. They must be painstakingly learned.

This education in visual perception has been addressed particularly in ethnographically based efforts to understand how specific people see their environment and why they do so in particular ways. Christina Grasseni, in her fieldwork among breeders of dairy cattle in the Italian Alps, paid attention to how the research participants were able to identify a particular person's bovine on sight and how they developed criteria for assessing the animals' beauty. She pointed out that a focus on the 'educated capacity for looking at cattle' was for her 'a necessary premise to access their worldview' (2004, p. 42), meaning that studying specific ways of looking enabled her to gain an understanding of how her research subjects approached their worlds. 
While these participants were enculturated early into communities of practice, with breeders' children playing games such as cow-spotting, and maintained frequent contact with other skilled practitioners in their social networks (e.g. accomplished breeders), Grasseni recognised also the importance of devices that codify expression and help guide visual attention. She lists blueprints for the 'ideal cow', specifying the defining characteristics of the breed (including a model of the ideal Italian Brown available on line); diagrams highlighting each trait to be considered for morphological evaluation; sketches highlighting the preferrable manifestation of a trait; computerised programs whose algorithms compute the incidence of each trait toward the overall score (e.g. the udder weighs against 40 per cent of the total score); amateur and professional videos made by breeders at cattle fairs [...]; eloquent and colourful adverts for bull semen; registers of bulls, heifers, calves and embryos, listed in order of their 'genetic indexes' (Grasseni, 2004, p. 44).

These devices orient and structure attention, thereby supporting social co-operation over time and space. While communities of practice necessarily rely on other people to thrive, Grasseni's work shows how they also use a variety of artefacts, including a range of media, to learn and for knowing what to look at.

Diana Eck too (2007) has worked on understanding ways of looking in an ethnographic context, in her case with attention to Darśan in an Indian village, a particular way of seeing the divine. Her work illustrates how our conceptions of seeing as something we actively do, whether because of a situational task or because of our enskilment into a specific way of looking, are themselves cultural constructs. In her research, Eck noticed her informants talking about seeing divine images as 'taking darśan', whereas she might have thought of the participants as actively looking at a deity in an image. This taking of Darśan was understood in a broader religious context, in which a deity is 
thought to present itself to be seen. In this way of looking, one encounters an act initiated not by the research participants but by the deity granting the seeing. Situational agency is given not to the person looking at an image of the divine but to the divinity that makes itself seen. The medium of the look is in this case taken over by an agent that is given access to what is situationally seen. This understanding of a look differs from that of an active subject searching proactively for meaning in images.

Eck's case study is of particular importance since it allows us to reconsider the mediations that render looking understandable, be they the camerae obscurae, eye-tracking technology, or the list of devices that codify expression and take part in guiding visual attention. Just as these devices have been used for very different kinds of understandings of how vision and the human mind work, it may be worth reconsidering understandings of who sees whom when attending to powerful images, such as those that Eck examined. Thinking in terms of the look as a medium affords pointing to different understandings of seeing, taking into account historical and geographical context.

\section{Looking into each other's eyes}

An understanding of the look as a medium, as outlined above, underscores the importance of focusing on the interrelations among those looking, what is looked at, and the wider contexts within which this particular looking becomes understandable. In my efforts aimed at teaching this kind of approach in the university classroom, I have gone beyond reading related literature with students on the topics mentioned, as done above, when presenting the framework. I will now introduce one of the classroom exercises I have developed with the intent of ourselves acting as media to wonder about and possibly question specific ways of seeing. ${ }^{1}$ I have found this particular visual exercise, called 'looking into each other’s eyes’, especially useful for considering with students why an 
understanding of the look as a medium may be useful for reflecting on the importance of studying visual cultures.

In the exercise, developed for addressing the affective, visual, and socially regulated forms of looking, I ask the students to engage in an exercise, which unfolds step by step. ${ }^{2}$ I have stressed that these are voluntary exercises, noting that one may decide not to perform them if finding them potentially uncomfortable or feeling that they may not be personally suitable.

Firstly, I ask the students to turn toward the person seated next to them and, with an open mind, look into that person's eyes for 60 seconds. They are asked not to speak while doing so and just to focus on what happens when they do as asked. After this, we discuss their findings.

In the first step, we focus on how the look operates as a medium of images - in particular, how looking into someone's eyes is an activity that enables us to discuss fundamental questions pertaining to looking and being looked at. In our discussions, the students tend to notice a heightened affectivity, a specific kind of emotional energy, with some starting to laugh during the task, others averting their gaze after a time, and some focusing on each other's look in explorative ways. Laughing, turning away, and exploring the other person's look in novel ways are explained by the students in terms of feeling awkward, 'funny', or uncomfortable or in relation to being interested in the openings the task allows for. In our discussion, students reflect on the look as an act that is more than plain physiology, an act that is socially regulated, policed, and at times contested. The situational look is itself a medium of social asymmetries, one that the students have become skilled at adhering to, in ways that depend on specific tasks and the students' respective cultural backgrounds. Also, the look is considered to be something potentially dangerous, since someone gazing into one’s eyes for ‘too long' could perhaps get 'too close', which might start to 
feel uncomfortable. While the look has potential for danger, it may also arouse positive sentiments: some students muse that they started to feel sympathy toward the neighbours they were looking at, students with whom they might never have had prolonged social interaction of any sort. Here, the look is understood as socially constrained, and these interpersonal interactions allow us to consider questions of the gaze, a much-discussed topic in the field of visual cultures.

Besides focusing on the social aspects of the look, this step allows students to reflect on seeing as a physiological process, because they tend to notice that they have difficulties in focusing on the look of the other person per se and instead need to, for example, choose which eye to focus on, since the distance between the two students leaves only one eye sharply visible. Some who start to explore the look and do not turn away (for example, laughing) notice the kinds of eye movements they make in looking at the other's face. They might focus mainly on one eye of the person to be looked at, while glancing every now and then at the other eye, or they might start to explore other facial features, such as the cheekbones, nose, or eyebrows, perhaps noticing scars, pimples, or other specifics of the face that is looking at them.

Secondly, I ask the students to have one in each pair take a mobile camera-phone out, point it at the other person with the camera function active, and repeat the task from step 1 . They are told not to take photos of each other, but to focus on each other, this time mediated via the mobile cameraphone. Again, we discuss their findings after 60 seconds elapse.

The second part of the task allows the students to reflect on how the look becomes understandable via its mediations, rendering them able to compare the experience of looking directly into each other's eyes with this second step, using one mobile camera-phone between them. The additional mediation of the look, due to one of the participants looking at the other person via a mobile 
camera-phone, is described by the students as bringing about various changes in their social interaction as they begin to look into each other's eyes.

Discussing the second step in the exercise, the students tend to identify changes in the emotional energy of looking at each other, which is felt to be more intense without the mobile camera-phone: the camera 'cools off' some of the possible danger or positive arousal from interpersonal interaction. A direct look, into each other's eyes, allows for a strong connection between those looking at each other, an attachment that is affectively experienced. A medium in between, such as the mobile camera-phone, changes this relationship.

Interestingly, when this exercise was used several years ago, many students under the cameraequipped eye felt uncomfortable unless they were used to being filmed in connection with their work, for instance, having experience working on television or as a model for advertisements. This feeling of discomfort was explained as resulting from asymmetric power relations: in situations of this sort, students without the camera-phone do not know what the other person is actually looking at, because the person with the camera is focusing on the device's screen. Also, concerns were voiced as to what might be done in similar situations with pictures taken, since outside of the exercise setting it is often impossible to know if someone has taken pictures or shared them further. In contrast, when I have led this task with students more recently, considerably fewer have spoken of such a feeling of discomfort when being filmed, possibly on account of the increasing prevalence of mobile camera-phone use in various other social situations, with students possibly getting more used to being in front of the camera.

Meanwhile, those behind the camera during this task describe a feeling of being much freer in exploring the eyes and face of the person to be looked at and of not needing to adhere to as many 
social constraints when doing so. In the discussions, the position of social power in being able, and allowed, to see, via a technical mediation, is particularly subject to reflection, also in its broader societal implications. Some students tend to note power asymmetries between those seeing and those being seen, and these prompt reflection on ways in which, for example, social-media services have operationalised this dynamic relationship. This step allows us to discuss how different media affect social interaction, by students explicitly feeling a difference in a look mediated by a mobile camera-phone, as compared to one directly into each other's eyes.

Thirdly, I ask both participants to use a mobile camera-phone for looking into the other person’s eyes. Since both use mobile camera phones for doing so, both tend to focus on each other's eyes as they are rendered on the screen of the mobile device. Again, we discuss the findings afterward, taking the additional layer of mediation into account.

During this step, we discuss how visual media are media created to be looked at, affecting even real-time interactional seeing. While students tend to notice a heightened symmetry when both use mobile camera-phones, they note also the effect of the devices between them. These act as additional shields, further cooling off the felt intensity of a prolonged gaze into each other's eyes. These observations often lead the participants to reflect on the wider societal implications of camera use, such as who is able to capture images, in which kinds of situations, and for what kinds of purposes.

These discussions are often complemented with reflections on elements of visual infrastructure, such as the role of access to fast telecommunication networks, or the number of screens in urban spaces. The prevalence of surveillance cameras, mobile camera-phones, and media events at which 
cameras are employed for public relations and journalistic purposes is brought up. This then is discussed in terms of the societal relations that these camera uses entail.

These broader societal questions gain greater prominence in the discussion when an additional step is added, connecting one of the mobile camera-phones to a projector, so that one of the faces depicted can be streamed on a classroom wall. While the mediated look in this form is particularly impressive - in that one of the faces depicted is now not miniaturised (as it is when viewed via a mobile phone's screen) but amplified, making the face again visible in novel ways - step 4 is often less technically feasible in classroom situations. Accordingly, I have usually focused on the first three steps of the exercise.

For developing visual pedagogy approaches for university classrooms, this exercise has shown strong potential to generate discussions and insight on visual cultures. While findings from individual students vary, the exercise prompts wide-ranging discussions on visuality, aiding in asking fundamental questions about seeing, both in individual-level and in broader societal and cultural contexts. Importantly for classroom purposes, it allows students to share a common experience of analysing visual cultures, providing a frame of reference that can be discussed when they are critically reading related literature. The task arouses emotional energy, since 60 seconds of gazing into each other's eyes is not a common, everyday act. Discussing this arousal motivates students to reflect on what is happening during the task. That situational reflection can then be guided toward reflection on broader questions pertaining to visual cultures. An element of interdisciplinarity adds practical utility in this connection, since discussion of such questions tends to be scattered across several disciplines and relevant literature might therefore be difficult for students to find. 


\section{Teaching the look as a medium}

Teaching the look as a medium by asking students to look into each others' eyes and then repeating the task with a range of technical artefacts, as with one student holding a mobile camera-phone up to look at the other, then both using a mobile camera-phone, and finally one of the images being shown on a larger screen, is useful for discussing, and further elaborating on, key questions related to our visual cultures and the relations we form and occupy within them.

The individual steps of the task are useful for showing and discussing how the look changes, depending on the ways in which it is mediated. While altering one aspect of the mediation has an impact on how we look at each other, efforts to create a form of emotional energy similar to what is experienced eye-to-eye call for focusing on specific changes in 'how we see, how we are able, allowed, or made to see, and how we see this seeing or the unseen therein' (Foster, 1988, p. ix). This broadens our discussion to questions that are not purely technical, ones that deal with social constraints, values, and possibilities in relation to forms of accepted ways of looking, which differ with how we perform the looking. The initial look thereby becomes understandable in relation to its situational mediations, as discussed at the start of this paper and experienced by the students in the task.

Focusing on 'how we are able, allowed, or made to see', by emphasising the mediations of the look, helps us start to pay attention to the specifics of media that are explicitly created to be looked at. Against an understanding of the close connections between bodies and images, between images in corpore and images in effigy, as outlined above, our faces provide a particularly good access point for considering them as especially attractive media to be looked at. Related research on visual attention demonstrates that faces tend to be quickly noticed; they are attention machines, as discussed by Valentin Groebner (2015). Faces can hence be considered visual media par excellence. 
But so are displays for mobile phones, though increasingly equipped with haptic technologies (Parisi et al., 2017). In most cases, they are made to be looked at and subsequently acted upon, using vision and haptics in interaction chains. And frequently it is the embedded human face that is integral to these mobile camera-phone technologies (Kember, 2014), in a way making sure that the displays are indeed used as visual media, as indeed is done in the visual exercise.

With an awareness of the interrelations between our understanding of the look and its mediations, as well as a focus on visual media as media to be looked at, the exercise sparks a discussion of how the look acts as a medium of images, depending on what we focus on when looking each other in the eyes. Whether found in someone else's pimples, the pupil of the eye, or the wrinkles in the skin, all points of focus provide us with distinct images of who the person opposite us is, what he or she looks like. Once this interrelation is technically mediated by means of a mobile camera-phone, the mediations of the look may distract how we look at each other, making it difficult to regain the intensity of looking someone eye-to-eye. In addition, this mediation affects what we pay attention to, and thus what kinds of images we see.

With the students, looking, as experienced in the exercise, is then discussed as a skilled practice, differing with how we are used to looking and to being looked at. While some students, thanks to experience such as standing in front of a camera in professional capacity, have learned ways of being depicted that they feel comfortable with, not all know how to perform visual orders (Seppänen, 2006) that seem to make sense to them. That these visual orders are more often than not rendered asymmetrical, helping to continue patterns of interaction that are discriminatory, comes up in classroom discussions of the exercise and is discussed in related literature. Skilled vision, hence far from being just a way of knowing and showing how the world possibly is, is an enskilment into communities of practice, and thus into social hierarchies. 


\section{Conclusions}

An analytical framework, considering the look as a medium, is helpful for guiding students' research to take both the people studied and the visual media they use into account. By focusing on, firstly, how the look becomes understandable via its mediations, students can consider various medium-theoretical literature in their strivings to reflect fully on what kinds of media actually render looking visible. Thus, they can problematise the ways in which the visibility of the look is influenced by the particular media used to understand it. By reflecting, secondly, on the suggestions given as to how visual media are to be looked at, students focus on the actual images shown and on the differences that particular visual media make in providing surfaces for images. Learning in this connection comes particularly through literature in the domain of visual cultures and Bildwissenschaft, which tends to focus on questions related to an analysis of particular images and their specific histories. Through a third area of focus, the ways in which the look acts as a medium of images, students are able to form a synthesis between the above-mentioned literature and research into visual perception, which tends to put its emphasis on the physiology of vision. Finally, this literature needs to be complemented with culturally sensitive ethnographic accounts, exploring looking as a skilled practice, in which common, seemingly universal conceptions of vision might be questioned.

The exercise called 'looking into each other's eyes' provides a way to affectively engage students with questions cutting to the heart of visual cultures, by focusing explicitly on the look as a medium. Once possessing the experience of the exercise, students have a shared way of assessing related literature on visual cultures, helping them to think about possible empirical case studies they might conduct as part of the class or about further work later on. 
While the exercise and the analytical framework have been considered to be helpful for studying, researching, and teaching visual cultures, I believe that a focus on the look as medium helps us also to reflect as researchers and teachers with regard to the fundamental importance of basic social interactions, such as that of looking into each other's eyes. Too often, our studies may be set apart from the everyday for us, and we may tend to forget to reflect on who it is we look at, in what situations, and through what kinds of mediations. Every now and then, we might want to ask: How do you actually know what you see?

\section{Acknowledgements}

I would like to thank the students, with whom I have been able to develop this work on the look as a medium, as well as Anna Shefl for thorough proofreading and Seija Ridell for discussions.

\section{Notes}

1. W. J. T. Mitchell's (2002) article 'Showing Seeing' has served as inspiration for the development of my own exercises.

2. I have applied this exercise in university seminars at UC Berkeley, Humboldt-Universität zu Berlin, the University of Helsinki, and the University of Tampere.

\section{References}

Belting, H. (2011). An anthropology of images: Picture, medium, body, translated by Thomas Dunlap. Princeton, NJ: Princeton University Press.

Belting, H. (2014). Faces. Eine Geschichte des Gesichts. 2. Auflage [Faces: A story of the face, 2nd edition]. Wemding, Germany: C.H. Beck.

Bundesen, C., \& Habekost, T. (2008). Principles of visual attention. Linking mind and brain. New York, NY: Oxford University Press. 
Bredekamp, H. (2015). Der Bildakt [The picture act]. Berlin: Verlag Klaus Wagenbach.

Crary, J. (1992). Techniques of the observer: On vision and modernity in the nineteenth century. Cambridge, MA: MIT Press.

Eck, D. L. (2007). Darśan: Seeing the divine image in India. Delhi: Motilal Banarsidass.

Foster, H. (1988). Preface. In Ibid. (Ed.), Vision and Visuality (pp. ix-xiv). Seattle, WA: Bay Press.

Grasseni, C. (2004). Skilled vision: An apprenticeship in breeding aesthetics. Social Anthropology, 12(1), 41-55.

Groebner, V. (2015). Ich-Plakate: Eine Geschichte des Gesichts als Aufmerksamkeitsmaschine [I posters: A history of the face as an attention machine]. Frankfurt: S. Fischer.

Ingold, T. (2000). Stop, look and listen! Vision, hearing and human movement. In The Perception of the environment: Essays on livelihood, dwelling and skill (pp. 243-287). London, UK: Routledge.

Kember, S. (2014). Face recognition and the emergence of smart photography. Journal of Visual Culture, 12(2), 182-199.

Kittler, F. (2010). Optical media. Cambridge, UK: Polity.

Leroi-Gourhan, A. (1993). Gesture and speech, translated from the French by Anna Bostock Berger and introduced by Randall White. Cambridge, MA: MIT Press.

Lutz, C. A., \& Collins, J. L. (1993). Reading National Geographic. Chicago, IL: University of Chicago Press.

Mack, A., \& Rock, I. (1998). Inattentional blindness. Cambridge, MA: MIT Press.

Mitchell, W. J. T. (2002). Showing seeing: A critique of visual culture. Journal of Visual Culture, 1(2), 165-181.

Parisi, D., Paterson, M., \& Archer, J. E. (2017). Haptic media studies. New Media \& Society, 19(10), 1513-1522. 
Peters, J. D. (2015). The marvelous clouds: Toward a philosophy of elemental media, Kindle edition. Chicago, IL: University of Chicago Press.

Rose, G. (2011). Visual methodologies: An introduction to the interpretation of visual methods, third edition. London, UK: SAGE Publications.

Seppänen, J. (2006). The power of the gaze: An introduction to visual literacy, New York et al.: Peter Lang.

Simons, D. J., \& Chabris, C. F. (1999). Gorillas in our midst: Sustained inattentional blindness for dynamic events. Perception, 28, 1059-1074.

Yarbus, A. L. (1965/1967). Eye movements and vision, translated from Russian by Basil Haigh. New York, NY: Plenum Press. 